\begin{tabular}{|c|c|c|}
\hline 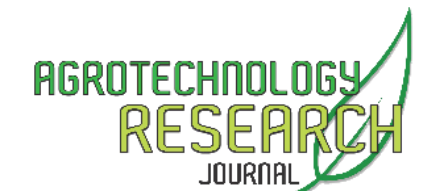 & $\begin{array}{c}\text { Agrotech Res J, June } 2019,3(1): 23-27 \\
\text { AGROTECHNOLOGY RESEARCH } \\
\text { JOURNAL }\end{array}$ & $\begin{array}{l}\text { ISSN 2655-7924 (Print) } \\
\text { ISSN } 2614-7416 \text { (Online) } \\
\text { https://jurnal.uns.ac.id/arj } \\
\text { doi:10.20961/agrotechresj.v3i1.30012 }\end{array}$ \\
\hline
\end{tabular}

\title{
Produksi Empat Varietas Padi Sawah yang Diberi Kombinasi Pupuk Bio- Slurry dan NPK
}

\author{
Yafizham ${ }^{1 *}$, Dwi Retno Lukiwati ${ }^{2}$ \\ 1,2Faculty of Animal and Agricultural Sciences, Universitas Diponegoro, Semarang, Indonesia \\ ${ }^{*}$ Corresponding Author: \\ E-mail: yafiz60@yahoo.com
}

Received 14 May 2019; Accepted 20 June 2019; Published 30 June 2019

\begin{abstract}
Non-organic agriculture has succeeded in increasing the production of lowland rice, but on the other hand also has a negative impact on the ecosystem of agriculture and the environment, such as the decreasing content of soil organic matter. One effort that can be done, is by adding bio-slurry organic fertilizer to the NPK fertilizer. This study was conducted to determine the effect of the combination of bio-slurry fertilizer and NPK fertilizer on the production of four rice paddy varieties. This research by experiment was conducted in Screen House Agrotechnopark, Faculty of Animal Husbandry and Agriculture, Diponegoro University, Tembalang Semarang campus, taking place from October 2018 to January 2019. The experiment used a randomized completely block design with two factors and three replications. The first factor was a combination of bio-slurry + NPK fertilizer ie without N (P0) fertilizer, NPK 550 $\mathrm{kg} \mathrm{ha}^{-1}$ fertilizer (P1), bio-slurry fertilizer 3 tons ha-1 + NPK fertilizer $400 \mathrm{~kg} \mathrm{ha}^{-1}, 6$ tons ha-1 bio-slurry fertilizer +250 $\mathrm{kg} \mathrm{ha}^{-1} \mathrm{NPK}$ fertilizer, 9 tons ha-1 bio-slurry fertilizer $+100 \mathrm{~kg} \mathrm{ha}^{-1} \mathrm{NPK}$ fertilizer and 12 tons bio-slurry fertilizer ha-1. Whereas the second factor was the lowland rice varieties namely Inpari 23, Sultan Unsrat, Sintanur and Gilirang. The results of the variance analysis showed that the combination of bio-slurry + NPK fertilizer and lowland rice varieties had a very significant effect on grain yield per clump, number of filled grains, number of empty grains, total grain count, weight of 1000 grains, rice yield per pot and harvest index. The highest grain yield per clump $(85.33 \mathrm{~g})$ was obtained from the treatment of $550 \mathrm{~kg} \mathrm{ha}^{-1} \mathrm{NPK}$ fertilizer, while the highest grain yield per clump (58.06 g) was obtained from the Gilirang variety (V4), the highest total grain amount (174.58 grains) was obtained from the treatment of NPK $550 \mathrm{~kg} \mathrm{ha}^{-1}$ and (212.28 grains) fertilizer produced by varieties Inpari 23 . The highest yield per pot of rice $\left(61.83 \mathrm{~g}\right.$ ) was obtained from the treatment of $550 \mathrm{~kg} \mathrm{ha}^{-1} \mathrm{NPK}$ fertilizer , while the highest paddy rice varieties which produced rice per pot of (63.22 g) were Inpari 23.
\end{abstract}

(c) 2019 Agrotechnology Research Journal

Keywords: Lowland rice; Bio-slurry; NPK

Cite This As: Yafizham, Lukiwati DR. 2019. Produksi Empat Varietas Padi Sawah yang Diberi Kombinasi Pupuk Bio-Slurry dan NPK. Agrotech Res J 3(1): 23-27. https://doi.org/10.20961/agrotechresj.v3i1.30012

\section{PENDAHULUAN}

Pemberian stimulan organik dan pupuk anorganik serta penggunaan varietas yang sesuai dapat meningkatkan produksi padi sawah. Penggunaan pupuk organik dapat diterapkan dalam upaya meningkatkan pertumbuhan dan produksil padi sawah melalui perbaikan sifat fisik dan kimia tanah. Salah satu upaya yang dapat dilakukan untuk meningkatkan pertumbuhan dan produksi padi sawah adalah melalui penambahan pupuk organik bio-slurry. Pupuk organik bio-slurry adalah produk akhir pengolahan kotoran ternak yang

This is an open access article Licensed under the Creative Commons Attribution International License CC-BY-SA 4.0

(c) EY-sA bermanfaat sebagai sumber nutrisi bagi tanaman. Bioslurry mengandung nutrisi utama (makro) yang diperlukan tanaman seperti NPK (nitrogen, fosfor dan kalium) dan nutrisi pelengkap (mikro) seperti magnesium $(\mathrm{Mg})$, kalsium (Ca), dan sulfur (S) (International Training Workshop 2010). Penggunaan pupuk organik saja, tidak dapat meningkatkan produktivitas tanaman pangan dan ketahanan pangan. Oleh karena itu, sistem hara terpadu yang memadukan pemberian pupuk organik atau pupuk hayati dan pupuk anorganik dalam rangka meningkatkan produktivitas dan kelestarian lingkungan perlu digalakkan. Hanya dengan cara ini keberlanjutan produksi tanaman dan kelestarian lingkungan dapat dipertahankan (Simanungkalit dan Suriadikarta 2006).

Masalah yang sering dihadapi oleh para petani yaitu tentang penurunan kesuburan lahan akibat pemberian pupuk anorganik yang berlebihan. Penggunaan pupuk 
anorganik secara terus-menerus dan berlebihan, tanpa diimbangi pupuk organik dapat mengakibatkan penurunan kualitas sifat fisik, kimia, dan biologi tanah sehingga menurunkan kesuburan tanah (Padmanabha et al. 2014). Menurut Hatta dan Rosmayati (2015) sampai saat ini produktivitas padi sebagian besar masih didukung oleh penggunaan pupuk kimia. Ketergantungan tersebut akan memberikan dampak buruk dalam jangka panjang, baik terhadap lingkungan maupun ekonomi. Ketergantungan terhadap pupuk kimia makin tinggi seperti dikemukakan oleh Santoso (2015), bahwa produksi beras nasional saat ini sangat dipengaruhi oleh realisasi subsidi pupuk kimia, yaitu urea, SP36, dan ZA.

Upaya untuk menghindari efek negatif tersebut perlu dilakukan, salah satunya dengan pemberian pupuk anorganik dan pupuk organik secara berimbang. Keuntungan dari applikasi kombinasi kedua jenis pupuk tersebut adalah kekurangan sifat pupuk organik dipenuhi oleh pupuk anorganik, sebaliknya kekurangan pupuk anorganik dipenuhi oleh pupuk organik. Penggunaan pupuk organik sangat dianjurkan karena dapat mengembalikan sifat-sifat tanah, memperbaiki struktur tanah, meningkatkan kesuburan dan menggemburkan tanah yang telah padat karena efek penggunaan pupuk anorganik atau pupuk kimia.

\section{BAHAN DAN METODE}

Penelitian ini dilaksanakan di Screen House Agrotechnopark Fakultas Peternakan dan Pertanian Universitas Diponegoro kampus Tembalang Semarang Jawa Tengah, berlangsung mulai bulan Oktober 2018 sampai Januari 2019. Bahan-bahan yang digunakan dalam penelitian ini adalah pupuk bio-slurry, pupuk NPK Mutiara, varietas padi sawah (Inpari 23, Sultan Unsrat, Sintanur dan Gilirang) yang diperoleh dari laboratorium Fisiologis dan pemuliaan tanaman Fakultas Peternakan dan Pertanian Universitas Diponegoro. Alat-alat yang digunakan dalam penelitian ini adalah pot plastik, tanah sawah, selang air, meteran, kamera, oven, timbangan analitis dan alat tulis menulis. Pot yang digunakan dalam penelitian ini adalah pot plastik yang berdiameter alas $24,5 \mathrm{~cm}$, diameter permukaan atas $28,5 \mathrm{~cm}$ dan tinggi 20 $\mathrm{cm}$, sebanyak 72 buah.

Percobaan ini menggunakan rancangan acak lengkap (RAL) terdiri atas dua faktor yaitu kombinasi pupuk bio-slurry + pupuk NPK terdiri atas tanpa pupuk (P0), pupuk NPK $550 \mathrm{~kg} \mathrm{ha}^{-1}$ (P1), pupuk bio-slurry 3 ton $\mathrm{ha}^{-1}+$ pupuk NPK $400 \mathrm{~kg} \mathrm{ha}^{-1}$ (P2), pupuk bio-slurry 6 ton ha-1 + pupuk NPK $250 \mathrm{~kg} \mathrm{ha}^{-1}$ (P3), pupuk bio-slurry 9 ton ha-1 + pupuk NPK $100 \mathrm{~kg} \mathrm{ha}^{-1}$ (P4) dan pupuk bioslurry 12 ton ha-1 (P5). Faktor kedua adalah varietas padi sawah yaitu Inpari 23 (V1), Sulutan Unsrat (V2), Sintanur (V3) dan Gilirang (V4). Jumlah total adalah 24 kombinasi perlakuan, tiap perlakuan diulang tiga kali sehingga diperoleh 72 satuan percobaan. Pot plastik media tanam diisi masing-masing $10 \mathrm{~kg}$ tanah sawah. Bibit dipindah tanam ke pot plastik setelah berumur 15 hari setelah semai (HSS), sebanyak 3 bibit per pot dan disisakan 1 bibit apabila tanaman sudah mulai tumbuh dengan baik. Pupuk bio-slurry diberikan 1 minggu sebelum tanam sedangkan pupuk NPK diberikan dua kali, yaitu $60 \%$ pada 5 hari setelah tanam (HST) dan $40 \%$ pada $35 \mathrm{HST}$.

Parameter yang diamati adalah hasil gabah per rumpun, jumlah gabah isi, jumlah gabah hampa, jumlah gabah total, bobot 1000 butir, hasil padi per pot, dan Indeks panen. Analisis data menggunakan sidik ragam, apabila dalam sidik ragam pada taraf 5\% terdapat pengaruh nyata maka dilanjutkan dengan uji DMRT (Duncan Multiple Range Test).

\section{HASIL DAN PEMBAHASAN Hasil Gabah per Rumpun}

Hasil analisis statistik menunjukkan bahwa interaksi antara kombinasi pupuk bio-slurry dan pupuk NPK dengan keempat varietas padi sawah terhadap seluruh parameter yang diamati tidak berbeda nyata. Perbedaan nyata terjadi pada setiap kombinasi pupuk bio-slurry dan pupuk NPK maupun keempat varietas padi sawah terhadap hasil. Tabel 1 memperlihatkan bahwa parameter hasil gabah per rumpun pada perlakuan kombinasi pupuk bio-slurry dan pupuk NPK secara mandiri menunjukkan bahwa perlakuan pupuk NPK 550 $\mathrm{kg} \mathrm{ha}^{-1}$ menghasilkan hasil gabah per rumpun tertinggi yaitu $85.33 \mathrm{~g}$ dan berbeda nyata dengan perlakuan kombinasi pupuk bio-slurry + pupuk NPK lainnya, seperti perlakuan pemupukan bio-slurry 9 ton ha-1 + NPK $100 \mathrm{~kg}$ $\mathrm{ha}^{-1}$ menghasilkan tinggi tanaman sebesar $47.58 \mathrm{~g}$.

Hal ini menunjukkan bahwa unsur hara yang terdapat pada pupuk NPK bekerja optimal pada penambahan hasil gabah per rumpun. Pupuk anorganik NPK merupakan pupuk yang mudah dan dapat langsung tersedia bagi tanaman sehingga unsur hara yang terkandung dalam pupuk anorganik langsung dapat digunakan tanaman untuk menunjang produksi khususnya hasil gabah per rumpun. Sedangkan dari perlakuan keempat varietas padi sawah secara mandiri menunjukkan bahwa hasil gabah per rumpun tertinggi diperoleh dari varietas Gilirang yaitu $58.06 \mathrm{~g}$ dan hasil gabah per rumpun terendah diperoleh dari varietas Sulutan Unsrat (46.22 g).

\section{Jumlah Gabah Isi}

Jumlah gabah isi pada perlakuan kombinasi pupuk bio-slurry dan pupuk NPK dengan varietas padi sawah tersaji pada Tabel 1. Jumlah gabah isi tertinggi diperoleh dari perlakuan pupuk NPK $550 \mathrm{~kg} \mathrm{ha}^{-1}$ sebesar 144.67 biji tetapi tidak berbeda dengan jumlah gabah isi tanaman yang dipupuk dengan bio-slurry 3 ton ha-1 + NPK $400 \mathrm{~kg} \mathrm{ha}^{-1}$, bio-slurry 6 ton ha-1 + NPK $250 \mathrm{~kg} \mathrm{ha}^{-1}$ dan bio-slurry 12 ton ha-1 yaitu masing-masing sebesar 129.92 biji, 127.08 biji dan125.33 biji. Sementara perlakuan keempat varietas padi sawah menunjukkan bahwa varietas Inpari 23 menghasilkan jumlah gabah isi tertinggi sebesar 161.11 biji. Sedangkan jumlah gabah isi varietas Sulutan Unsrat, Sintanur dan Gilirang tidak berbeda nyata satu sama lainnya yaitu sebesar 108.94 biji, 107.39 biji dan 116.61 biji. 
Tabel 1. Pengaruh kombinasi pupuk bio-slurry dan NPK dengan keempat varietas padi sawah terhadap hasil gabah per rumpun, jumlah gabah isi, jumlah gabah hampa dan jumlah gabah total

\begin{tabular}{|c|c|c|c|c|}
\hline Perlakuan & $\begin{array}{c}\text { Hasil gabah } \\
\text { per rumpaun } \\
\text { (g) }\end{array}$ & $\begin{array}{c}\text { Jumlah gabah } \\
\text { isi } \\
\text { (biji) }\end{array}$ & $\begin{array}{c}\text { Jumlah gabah } \\
\text { hampa } \\
(\%)\end{array}$ & $\begin{array}{c}\text { Jumlah } \\
\text { gabah total } \\
\text { (biji) }\end{array}$ \\
\hline \multicolumn{5}{|l|}{ Pemupukan } \\
\hline Tanpa pupuk (P0) & $28,92 d$ & $94,33 \mathrm{c}$ & $26,25 a$ & $120.58 c$ \\
\hline NPK $550 \mathrm{~kg} \mathrm{ha}^{-1}(\mathrm{P} 1)$ & $85,33 a$ & $144,67 a$ & $29,92 a$ & $174,58 a$ \\
\hline bio-slurry 3 ton ha-1 + NPK $400 \mathrm{~kg} \mathrm{ha}^{-1}(\mathrm{P} 2)$ & $61,67 b$ & $129,92 a b$ & $31,83 a$ & $162,25 a b$ \\
\hline bio-slurry 6 ton ha-1 + NPK $250 \mathrm{~kg} \mathrm{ha}^{-1}(\mathrm{P} 3)$ & $53,67 \mathrm{bc}$ & $127,08 a b$ & $25,92 a$ & $153,00 a b$ \\
\hline bio-slurry 9 ton ha-1 + NPK $100 \mathrm{~kg} \mathrm{ha}^{-1}(\mathrm{P} 4)$ & $47,17 \mathrm{c}$ & $125,33 a b$ & $30,50 a$ & $150,25 b$ \\
\hline bio-slurry 12 ton ha-1 $(\mathrm{P} 5)$ & 43,17 & $125,33 a b$ & $19,50 a$ & $144,83 b$ \\
\hline \multicolumn{5}{|l|}{ Varietas } \\
\hline Inpari 23 (V1) & $57,11 a b$ & $161,11 a$ & $50,83 a$ & $212,27 a$ \\
\hline Sulutan Unsrat (V2) & $46,22 b$ & $108,94 b$ & $15,17 \mathrm{c}$ & $124,11 \mathrm{c}$ \\
\hline Sintanur (V3) & $52,16 a b$ & $107,39 b$ & $16,22 \mathrm{c}$ & $123,61 c$ \\
\hline Gilirang (V4) & $58,06 a$ & $116,61 b$ & $27,06 \mathrm{~b}$ & $143,67 b$ \\
\hline
\end{tabular}

Keterangan: Angka dalam satu kolom yang diikuti huruf sama tidak berbeda nyata menurut DMRT 5\%.

Menurut Totong et al. (2015) peningkatan aplikasi dosis sampai $400 \mathrm{~kg}$ pupuk anorganik ha-1 akan meningkatkan ketersediaan unsur hara terutama $\mathrm{N}, \mathrm{P}$, dan $\mathrm{K}$ tanah. Komponen hasil dan hasil gabah dipengaruhi oleh fotosintesis tanaman, dimana proses ini dipengaruhi oleh unsur hara $\mathrm{N}, \mathrm{P}$, dan $\mathrm{K}$. Unsur $\mathrm{N}$ berfungsi meningkatkan kandungan klorofil daun tanaman sehingga proses fotosisntesis tanaman meningkat. Jumlah klorofil yang tinggi menunjukkan proses fotosintesis dapat berjalan dengan baik (Suharno et al. 2007; Ai dan Banyo, 2011). Hasil penelitian Dong et al. (2009); Zhang et al. (2011) menunjukkan bahwa pemberian $\mathrm{N} 60 \%$ pada tahap awal dan $40 \%$ tahap akhir menyebabkan meningkatnya ketersediaan $\mathrm{N}$ pada tahap pertumbuhan akhir yang dapat mempengaruhi metabolisme daun selama pengisian biji. Unsur $P$ berperan dalam suplai dan transfer energi seluruh proses biokimia padi, salah satunya yaitu mempercepat pemasakan dan perkembangan gabah sehingga bobot gabah meningkat. Unsur $\mathrm{K}$ berfungsi untuk pembentukan gula, zat tepung dan berbagai macam enzim sehingga jumlah gabah per malai dan persen gabah isi dapat ditingkatkan (Booromand dan Grough 2012).

\section{Jumlah Gabah Hampa}

Perlakuan kombinasi pupuk bio-slurry dan pupuk NPK tidak berpengaruh nyata terhadap jumlah gabah hampa tanaman padi sawah (Tabel 1). Sedangkan perlakuan empat varietas padi sawah berpengaruh nyata terhadap jumlah gabah hampa. Jumlah gabah hampa terendah diperolah dari varietas Sulutan Unsrat sebanyak $15.17 \%$ tetapi jumlah gabah hampa ini tidak berbeda nyata dengan yang dihasilkan varietas Sintanur (16.22\%).

Terdapat beberapa faktor yang mempengaruhi terjadinya gabah hampa di lapangan, di antaranya adalah tanaman terserang hama dan penyakit, tidak terjadi pembuahan, defisiensi unsur hara, dan kualitas benih yang digunakan. Keadaan di lapangan yang terjadi menunjukkan tingginya intensitas serangan hama walang sangit (Leptocorisa oratorius). Walang sangit menyerang bulir padi yang berusia muda dengan mengisap isi dari bulir padi. Warna bulir padi yang terserang menjadi kecoklatan dan pada saat tua bulir padi menjadi hampa. Varietas Sintanur memiliki ketahanan terhadap wereng biotip 1 dan 2 akan tetapi rentan terhadap serangan wereng cokelat [BBPADI, 2009]. Wereng cokelat mengisap cairan dari batang padi muda atau pada bulir-bulir muda yang lunak, dapat meloncat tinggi dan tidak terarah, berwarna cokelat dan berukuran 3-5 mm (Siregar 2001).

\section{Jumlah Gabah Total}

Jumlah gabah total pada perlakuan kombinasi pupuk bio-slurry dan pupuk NPK dengan varietas padi sawah tersaji pada Tabel 2. Jumlah gabah total tertinggi diperoleh dari perlakuan pupuk NPK $550 \mathrm{~kg} \mathrm{ha}^{-1}$ sebesar 221.50 biji dan jumlah gabah total tertinggi berikutnya diikuti oleh tanaman yang dipupuk dengan bio-slurry 3 ton ha-1 + NPK $400 \mathrm{~kg}$ ha $^{-1}$, sedangkan jumlah gabah total tanaman padi dipupuk bio-slurry 6 ton $\mathrm{ha}^{-1}+$ NPK $250 \mathrm{~kg} \mathrm{ha}^{-1}$, bio-slurry 9 ton ha ${ }^{-1}+$ NPK 100 $\mathrm{kg} \mathrm{ha}^{-1}$ dan bio-slurry 12 ton ha-1 tidak berbeda nyata. yaitu masing-masing sebesar 135.58 biji, 131.67 biji dan 122.08 biji. Ke empat varietas padi sawah tidak berpengaruh nyata terhadap jumlah gabah total.

Pemberian pupuk organik dapat mempengaruhi hasil tanaman padi jumlah gabah per malai, jumlah gabah isi per malai dan GKG) berhubungan dengan meningkatnya ketersediaan kalium dalam tanah dan serapan kalium oleh tanaman. selain itu juga ketersediaan unsur nitrogen dan fosfor di dalam tanah. Ketiga unsur makro ini merupakan unsur hara yang sangat penting dibutuhkan oleh tanaman, di mana interaksi ketiga unsur ini akan dapat menunjang pertumbuhan dan hasil padi sawah yang lebih baik. Fairhurst et al. 2007 menyatakan bahwa Kalium dapat meningkatkan jumlah gabah/malai, jumlah gabah isi/malai dan gabah kering giling (GKG). 
Tabel 2. Pengaruh pupuk bio-slurry dan NPK terhadap jumlah gabah total, bobot 1000 butir, hasil padi per pot dan indeks panen varietas padi sawah

\begin{tabular}{|c|c|c|c|c|}
\hline Perlakuan & $\begin{array}{c}\text { Jumlah gabah } \\
\text { total } \\
\text { (biji) }\end{array}$ & $\begin{array}{c}\text { Bobot } 1000 \\
\text { butir } \\
\text { (g) }\end{array}$ & (\%) & $\begin{array}{c}\text { Indeks } \\
\text { panen } \\
(\%)\end{array}$ \\
\hline \multicolumn{5}{|l|}{ Pemupukan } \\
\hline Tanpa pupuk (P0) & $72,25 d$ & $19,82 d$ & $61,72 a$ & $40,42 a$ \\
\hline NPK $550 \mathrm{~kg} \mathrm{ha}^{-1}(\mathrm{P} 1)$ & $221,58 a$ & $67,82 a$ & $61,83 a$ & $38,73 a$ \\
\hline $\begin{array}{l}\text { bio-slurry } 3 \text { ton ha-1 }+ \text { NPK } 400 \mathrm{~kg} \mathrm{ha}^{-1} \\
\text { (P2) }\end{array}$ & $170,96 b$ & $50,20 \mathrm{~b}$ & $59,58 b$ & $36,98 \mathrm{a}$ \\
\hline $\begin{array}{l}\text { bio-slurry } 6 \text { ton ha-1 }+ \text { NPK } 250 \mathrm{~kg} \mathrm{ha}^{-1} \\
\text { (P3) }\end{array}$ & $135,58 \mathrm{c}$ & $38,38 \mathrm{c}$ & $61,08 a b$ & $40,25 a$ \\
\hline $\begin{array}{l}\text { bio-slurry } 9 \text { ton ha-1 }+ \text { NPK } 100 \mathrm{~kg} \mathrm{ha}^{-1} \\
\text { (P4) }\end{array}$ & $131,67 c$ & $42,65 \mathrm{bc}$ & $61,83 a$ & $37,01 \mathrm{a}$ \\
\hline bio-slurry 12 ton ha-1 (P5) & $122,08 \mathrm{c}$ & $37,80 \mathrm{c}$ & 61,501 & $36,96 a$ \\
\hline \multicolumn{5}{|l|}{ Varietas } \\
\hline Inpari 23 (V1) & $139,83 a$ & $43,95 a$ & $63,22 a$ & $41,24 a$ \\
\hline Sulutan Unsrat (V2) & $133,72 a$ & $38,69 a$ & $59,33 c$ & $35,28 a$ \\
\hline Sintanur (V3) & $151,94 a$ & $41,99 a$ & $61,33 b$ & $35,77 a$ \\
\hline Gilirang (V4) & $143,86 a$ & $46,46 a$ & $61,28 \mathrm{~b}$ & $41,28 \mathrm{a}$ \\
\hline
\end{tabular}

Keterangan: Angka dalam satu kolom yang diikuti huruf sama tidak berbeda nyata menurut DMRT 5\%.

\section{Bobot 1000 Butir}

Bobot 1000 butir padi sawah pada perlakuan kombinasi pupuk bio-slurry dan pupuk NPK disajikan Tabel 2. Bobot 1000 butir tertinggi $(67.82 \mathrm{~g})$ diperoleh dari perlakuan pupuk NPK $550 \mathrm{~kg} \mathrm{ha}^{-1}$, yang diikuti dengan perlakuan kombinasi pupuk bio-slurry 3 ton ha-1 + NPK $400 \mathrm{~kg} \mathrm{ha}^{-1}$ dan bio-slurry 6 ton ha-1 + NPK 250 $\mathrm{kg} \mathrm{ha}^{-1}$ dengan masing-masing bobot 1000 butir sebesar $50.20 \mathrm{~g}$ dan $38.38 \mathrm{~g}$. Peningkatan bobot 1000 butir gabah isi dengan berbagai kombinasi perlakuan pemupukan dikarenakan peningkatan ketersediaan unsur $\mathrm{K}$ sehingga pengisian gabah pun sempurna. Sedangkan pengaruh keempat varietas padi sawah tidak berpengaruh terhadap bobot 1000 butir. Bobot 1000 butir pada hasil pengamatan panen tidak memberikan pengaruh yang nyata antar perlakuan varietas padi sawah. Gardner et al. (1991) menyatakan bahwa untuk pengisian biji dibutuhkan hasil fotosintat yang berasal dari daun dan aliran fotosintat dari bagian tanaman lainnya. Faktor yang menyebabkan kecilnya persentase gabah bernas pada penelitian ini adalah adanya faktor penyakit busuk leher pada malai sehingga translokasi fotosintat ke butir padi menjadi terhambat.

\section{Hasil Padi per Pot}

Hasil sidik ragam menunjukkan bahwa perlakuan kombinasi pupuk bio-slurry dan pupuk NPK berpengaruh nyata terhadap hasil padi per pot tanaman padi sawah (Tabel 2). Hasil padi per pot tertinggi $(61.83 \mathrm{~g})$ diperoleh dari perlakuan pupuk NPK $550 \mathrm{~kg} \mathrm{ha}^{-1}$, tetapi hasil ini tidak berbeda dengan perlakuan bio-slurry 9 ton ha- ${ }^{-1}+$ NPK $100 \mathrm{~kg} \mathrm{ha}^{-1}$, bio-slurry 12 ton ha-1 ${ }^{-1}$ dan tanpa pupuk yaitu masing-masing sebesar $61.83 \mathrm{~g}, 61.50 \mathrm{~g}$ dan 61.72 g. Sedangkan dari keempat varietas yang diuji varietas Inpari 23 menghasilkan hasil padi per pot tertinggi dibandingkan dengan ketiga varietas lainnya.

Menurut Gardner (1991) bahwa tinggi rendahnya pertumbuhan dan hasil tanaman sangat dipengaruhi oleh dua faktor yaitu faktor internal dan factor eksternal. Faktor internal merupakan faktor yang dipengaruhi oleh sifat genetik atau sifat turunan seperti umur tanaman, morfologi tanaman, daya hasil, kapasitas menyimpan cadangan makanan, ketahanan terhadap penyakit dan lain-lain. Faktor eksternal merupakan faktor lingkungan, seperti iklim, tanah dan factor biotik. Perbedaan pertumbuhan dan hasil yang diperoleh dipengaruhi oleh satu atau lebih dari faktor tersebut. Perbedaan susunan genetik merupakan salah satu faktor penyebab keragaman penampilan tanaman dan perbedaan susunan genetik akan selalu terjadi sekalipun bahan tanaman yang digunakan berasal dari jenis tanaman yang sama (Sitompul dan Guritno 1995). Hal ini sesuai dari hasil penelitian (Marzuki et al. 1997) juga menyatakan bahwa faktor lokasi, musim, varietas berpengaruh nyata terhadap pertumbuhan dan hasil tanaman.

\section{Indeks Panen}

Hasil analisis statistik menunjukkan bahwa perlakuan kombinasi pupuk bio-slurry dan pupuk NPK dengan keempat varietas padi sawah tidak berpengaruh terhadap indeks panen padi sawah (Tabel 2). Hal ini menunjukan bahwa indeks panen memiliki nilai yang rendah karena semua unsur hara lebih banyak menuju daun sehingga tanaman menjadi lebih subur tetapi produksi dari tanaman menjadi berkurang karena tanaman tersebut memiliki daun yang lebat dan memiliki jerami yang banyak pula. Perubahan cara budidaya padi dari cara anorganik hingga menjadi organik penuh membuat indeks panen padi menurun. Penurunan indeks panen disebabkan terdapat perbedaan nilai berat kering dan hasil panen saat perubahan cara budidaya padi dari cara konvensional hingga cara organik lebih dari 4 kali musim tanam. Selain itu juga dipengaruhi oleh kehilangan hasil. Kehilangan hasil panen merupakan 
faktor yang mempengaruhi tinggi rendahnya hasil panen perhektar tanaman padi.

\section{KESIMPULAN}

1. Kombinasi pupuk bio-slurry + pupuk NPK dan varietas padi sawah berpengaruh sangat nyata terhadap hasil gabah per rumpun, jumlah gabah isi, jumlah gabah hampa, jumlah gabah total, bobot 1000 butir, dan hasil padi per pot.

2. Hasil padi per pot tertinggi sebesar $(61,83 \mathrm{~g})$ diperoleh dari perlakuan pupuk NPK $550 \mathrm{~kg} \mathrm{ha}^{-1}$ (P1), Sedangkan varietas padi sawah yang menghasilkan padi per pot tertinggi sebesar $(63,22 \mathrm{~g})$ adalah varietas Inpari 23 (V1).

\section{DAFTAR PUSTAKA}

Ai NS, Banyo Y. 2011. Konsentrasi klorofil daun sebagai indikator kekurangan air pada tanaman. J. IImiah Sains. 11:166-173.

Booromand N, Grough MSH. 2012. Macroelements nutrition (NPK) of medicinal plants. J.Med. Plants Res. 6:2249-2255.

Balai Besar Penelitian Tanaman Padi Badan Penelitian dan Pengembangan Pertanian. Departemen Pertanian 2009. http://id.wikipedia.org/wiki/Padi. (10 september 2009).

Dewanto FG, Londok JJMR, Tuturoo RAV, Kaunang WB. 2013. Produksi Tanaman Jagung sebagai Isu Sumber Pakan". JURNAL : Fakultas Peternakan Universitas Sam Ratulangi Manado, 95115. Jurnal Zootek (“Zootek"Journal), Vol.32,No. 52013.

Dong GC, Wang YL, Juan Z, Biao Z, Zhang CS, Zhang YF, Yang LX, Huang JY. 2009. Characteristics of nitrogen distribution and translocation in conventional indica rice varieties with different nitrogen use efficiency for grain output. Acta Agron. Sin. 35:149155.

Fairhurst T, Witt C, Buresh R, Doberman A. 2007. Padi: Panduan Praktis Pengelolaan Hara. Diterjemahkan oleh A. Widjono. IRRI.

Gardner FP, Pearce RB, Mitchel R. 1991. Fisiologi Tanaman Budidaya. Universitas Indonesia

Hartatik W, Widowati LR. 1990. Pengaruh Pupuk Majemuk NPKS dan NPK terhadap Pertumbuhan dan Hasil Padi Sawah pada Inceptisol. Penelitian Pertanian Tanaman Pangan. Vol. 34 No. 3. 2015.

Hatta M, Rosmayati. 2015. Profil karakter tanaman padi populasi BULK generasi F4 pada kondisi kahat hara NPK. J. Floratek. 1(10):10-17. International Training Workshop.2010. Training Material of Biogas Technology. Yunan Normal University. Yunan, China. P102.

Kasniari DN, Supadma AN. 2007. Pengaruh Pemberian Beberapa Dosis Pupuk (N. P. K) dan jenis pupuk Alternatif terhadap Hasil Tanaman Padi (Oriza sativa. L) dan Kadar N. P. K inceptisol selemadeg. tabanan. Jurnal Agritop. (4): 168-176

Kaya E. 2013. Pengaruh Kompos Jerami Dan Pupuk Npk Terhadap N-Tersedia Tanah, Serapan-N,
Pertumbuhan, Dan Hasil Padi Sawah (Oryza Sativa L). Jurnal Agrologia. (2): $43-50$.

Leomo S, Sutariati GAK, Agustina. 2012. Uji kombinasi pupuk organik dan anorganik dalam pola leisa terhadap pertumbuhan dan hasil tanaman sorgum lokal pada lahan marginal. J. Agroteknos. 2 (3) : 166174.

Marzuki AR, Kartohardjono A, dan Siregar H. 1997. Potensi hasil beberapa galur padi resisten wereng batang coklat. Prosiding Simposium Nasional dan Kongres III PERIPI, Bandung 24-25 September 1997.

Mohanan KV, Mini CB. 2008. Relative contribution of rice tillers of different status towards yield. Int. J. Plant. Breed. Genet. 2:9-12.

Novira F, Husnayetti, Yoseva S. 2015. Pemberian pupuk limbah cair biogas dan urea, tsp, $\mathrm{kcl}$ terhadap pertumbuhan dan produksi tanaman jagung manis (Zea mayssacsharata Sturt.). JOM Faperta 2 (1) : 1 15.

Parman S. 2007. Pengaruh Pemberian Pupuk Organik Cair terhadap Pertumbuhan dan Produksi Kentang (Solanum tuberosum L.). Buletin Anatomi dan Fisiologi XV (2):I 21-31.

Padmanabha IG, Arthagama IDM, Dibia IN. 2014. Pengaruh dosis Pupuk Organik dan Anorganik Terhadap Hasil Padi (Oryza sativa L.) dan Sifat Kimia Tanah pada Inceptisol Kerambitan Tabanan. Ejournal Agroekoteknologi Tropika. 3(1):41-50.

Rauf AW, Syamsudin T, Sihombing SR. 2000. Peranan Pupuk NPK pada Tanaman Padi. Jurnal. Balai Besar Penelitian Tanaman Padi.

Santoso AB. 2015. Pengaruh luas lahan dan pupuk bersubsidi terhadap produksi padi nasional. J IImu Pertanian Indonesia. 20(3):208-212.

Simanungkalit RDM, Suriadikarta. 2006. Pupuk Organik dan Pupuk Hayati. Badan Penelitian dan Pengembangan Pertanian. Departemen Pertanian, Bogor.

Siregar AZ. 2007. Hama-Hama Tanaman Padi. Fakultas Pertanian. Universitas Sumatra Utara

Sitompul SM, Guritno B. 1995. Analisis Pertumbuhan Tanaman. Gadjah Mada University Press, Yogyakarta

Suharno, Mawardi I, Setiabudi, Lunga N, Tjitrosemito S. 2007. Efisiensi penggunaan nitrogen pada tipe vegetasi yang berbeda di stasiun penelitian Taman Nasional Gunung Halimun Jawa Barat. Biodiversitas 8:287-294.

Totong S, Sugiyanta, Melati M. 2015. Peran Pupuk Organik dalam Peningkatan Efisiensi Pupuk. J. Agron. Indonesia 43 (1) : 8 - 14 (2015).

Zhang JH, Liu JL, Zhang JB, Zhao FT, Cheng YN, Wang WP. 2010. Effects of nitrogen aplication rates on translocation of dry matter and nitrogen utilization in rice and wheat. Acta Agron. Sin. 36:1736-1742. 